\section{Factors Influencing Student Gains from Undergraduate Research Experiences at a Hispanic-Serving Institution}

\author{
Heather Daniels, ${ }^{\dagger}$ Sara E. Grineski, ${ }^{* *}$ Timothy W. Collins, ${ }^{\S}$ Danielle X. Morales," \\ Osvaldo Morera," and Lourdes Echegoyen" \\ 'Department of Sociology, University of Texas at El Paso, El Paso, TX 79968; :Department of \\ Sociology, Research Enrichment Core of BUILDing SCHOLARS, University of Texas at El Paso, \\ El Paso, TX 79968; ; Department of Geography, Institutional Development Core of BUILDing \\ SCHOLARS, University of Texas at El Paso, El Paso, TX 79968; "Research Enrichment Core of \\ BUILDing SCHOLARS, University of Texas at El Paso, El Paso, TX 79968; "Department of \\ Psychology, Student Training Core of BUILDing SCHOLARS, University of Texas at El Paso, El Paso, \\ TX 79968; \#Campus Office of Undergraduate Research, Administrative Core of BUILDing \\ SCHOLARS, University of Texas at El Paso, El Paso, TX 79968
}

\begin{abstract}
Undergraduate research experiences (UREs) confer many benefits to students, including improved self-confidence, better communication skills, and an increased likelihood of pursuing science careers. Additionally, UREs may be particularly important for racial/ethnic minority students who are underrepresented in the science workforce. We examined factors hypothetically relevant to underrepresented minority student gains from UREs at a Hispanic-serving institution, such as mentoring quality, family income, being Latino/a, and caring for dependents. Data came from a 2013 survey of University of Texas at El Paso students engaged in 10 URE programs ( $n=227$ ). Using generalized linear models (GzLMs) and adjusting for known covariates, we found that students who reported receiving higher-quality mentorship, spending more hours caring for dependents, and receiving more programmatic resources experienced significantly greater gains from their URE in all three areas we examined (i.e., thinking and working like a scientist, personal gains, and gains in skills). In two of three areas, duration of the URE was positive and significant. Being Latino/a was positive and significant only in the model predicting personal gains. Across the three models, quality of mentorship was the most important correlate of gains. This suggests that providing training to faculty mentors involved in UREs may improve student outcomes and increase program efficacy.
\end{abstract}

\section{INTRODUCTION}

Participation of undergraduate students in faculty-mentored research has been documented as a "high-impact" educational practice, which means that it has been widely tested and found to be beneficial for undergraduate students from a variety of backgrounds (Kuh, 2008). Undergraduate training programs centered on faculty-mentored research projects have been shown to promote gains among student participants in active learning, self-confidence, and pursuit of science careers (Lopatto, 2007; Lopatto and Tobias, 2010). Research experiences also increase students' critical-thinking and communication skills (Bauer and Bennett, 2003; Seymour et al., 2004; Hunter et al., 2007). Students are more likely to acquire critical-thinking and communication skills from participating in out-of-class research projects than they are from other activities, such as internships or course-based research projects (Thiry et al., 2011). Undergraduate research participants are thus better prepared to become science professionals than their peers (Laursen et al., 2010; Thiry et al., 2011).

Undergraduate research experiences (UREs) may be particularly important for racial/ethnic minority students (Russell et al., 2007; Jones et al., 2010), who are
Erin Dolan, Monitoring Editor

Submitted July 30, 2015; Revised February 22, 2016; Accepted February 23, 2016

CBE Life Sci Educ September 1, 2016 15:ar30

DOI: $10.1187 /$ cbe.15-07-0163

*Address correspondence to: Sara E. Grineski (segrineski@utep.edu).

(c) 2016 H. Daniels et al. CBE-Life Sciences Education () 2016 The American Society for Cell Biology. This article is distributed by The American Society for Cell Biology under license from the author(s). It is available to the public under an Attribution-Noncommercial-Share Alike 3.0 Unported Creative Commons License (http:// creativecommons.org/licenses/by-nc-sa/3.0) "ASCBß" and "The American Society for Cell Biology ${ }^{\prime \prime}$ are registered trademarks of The American Society for Cell Biology. 
underrepresented in higher education at the undergraduate level, in graduate school enrollment, and in terms of degree completion. UREs have been shown to have a bigger impact on underrepresented minority (URM) students than non-URM students in terms of aspirations to attend graduate school (Eagan et al., 2013), and URM students participating in research programs are more likely to persist in a science career than are URM students not doing research (Schultz et al., 2011). Qualitative evidence collected from high-achieving URM alumni of an undergraduate biology enrichment program demonstrated that UREs were critical in guiding their career choices; they pinpointed the URE experience as increasing their commitment to science in general and to their interest in pursuing a $\mathrm{PhD}$ (Villarejo et al., 2008).

A number of federally and privately funded undergraduate educational intervention programs focused on UREs have been implemented in the United States over the past three decades to increase the success of URM students in higher education and eventually in the science, technology, engineering, and math (STEM) labor market. This study examines factors that predict student gains from UREs among a sample of STEM undergraduate research program participants at the University of Texas at El Paso (UTEP). This study's focus on a Hispanic-serving institution (HSI), wherein nearly $90 \%$ of students are Hispanic/ Latino, enables examination of factors that might be particularly important for low-income URM student success. These factors include the duration of students' engagement in research programs, the quality of faculty mentoring provided to students, student ethnicity, English language deficiencies among students, caretaking responsibilities of students, student household income, student sex, and resources received by students through research programs.

Many studies have demonstrated an association between longer duration of UREs and greater student gains. For example, students who participated in undergraduate research programs over one summer reported gains in fewer areas than those completing a yearlong research experience (Adedokun et al., 2014). Additional studies have shown that, after completing 1 year in an undergraduate research program, students have read scientific literature, talked with senior scientists, and participated in regular lab meetings. These activities are hypothesized to help students integrate their understanding of underlying theories and concepts (Thiry et al., 2011). While benefits have been assessed for shorter-duration UREs, it has been argued that it takes three semesters in an undergraduate research program for students to build an identity as a scientist; after this much time, students begin to adopt the traits, habits, and temperament necessary to succeed along a scientific research path (Thiry et al., 2011).

Research and theory on mentoring suggest that the quality of mentoring is important for student gains, but there has been limited focus in the undergraduate research literature on the quality of the mentoring relationships in which students engage. Previous studies on URE student gains have focused primarily on quantifying the amount time students spend in faculty-mentored research programs or on assessing the gains associated with having versus not having a mentor (e.g., Schultz et al., 2011), rather than on the quality of the mentoring that occurs during this formative time (e.g., Hunter et al., 2007; Thiry et al., 2012). Outside the context of UREs, having a mentor (as opposed to not having one) has been associated with greater persistence and higher grade point average among college students (Jacobi, 1991; Campbell and Campbell, 1997; Crisp and Cruz, 2009; Crisp, 2010). In one of the few studies to examine the impact of mentoring over time, "hard science" doctoral students were asked to rate their advisers in terms of psychosocial mentoring, career-related mentoring, and research collaboration (i.e., invited coauthorship of research products). When participants were surveyed 3 years later, receiving higher levels of psychosocial mentoring predicted greater research self-efficacy (Paglis et al., 2006). However, few studies have assessed benefits associated with mentoring quality in student research experiences, and none to our knowledge have done so at the undergraduate level.

Apart from the duration of the URE and mentoring quality, other factors may be important correlates of student gains. Research indicates that HSIs are an important point of entry for Latino/a students in STEM fields (Crisp et al., 2009). Students at HSIs, including UTEP, are likely to be Latino/Hispanic, to not speak English at home, to be responsible for caring for dependents, and to have low incomes. These factors hypothetically influence gains from UREs, but they have not been comprehensively studied.

Racial/ethnic minority status is a factor that is likely to influence gains from UREs. At the University of California-Davis (a non-minority-serving institution [MSI]), Jones et al. (2010) found that Hispanic and African-American students (relative to other racial/ethnic groups) exhibited the largest gap in the probability of graduating with a biology degree between those who participated in URE versus those who did not, suggesting that URE participation may have provided increased benefits to students from those minority groups. By the fourth year of college, among students who had participated in a URE, Latino/as had higher aspirations for attending graduate programs than did whites (Eagan et al., 2013). In terms of student-reported gains, among summer research participants across 41 universities, URM students reported greater learning gains than their white/Asian peers, but rated their satisfaction with the overall experience the same (Lopatto, 2007).

Many students at MSIs face additional challenges, such as having family members who do not speak English and having to care for dependents. It is plausible that students who do not speak English at home might exhibit worse performance in UREs due to language challenges; however, we hypothesize that they stand to gain more from UREs than English as a first language students. This is because previous studies have demonstrated that students who did not speak English at home were more likely to persist in college and to receive more "A's" and fewer "F's" than those who grew up in families in which English was frequently spoken (Lohfink and Paulsen, 2005; Breckler et al., 2011). Many students attending HSIs have complicated family lives that include caretaking for dependents like children and elderly relatives. Among graduating UTEP seniors between 2008 and 2012, the average student provided $20 \mathrm{~h}$ of dependent care per week; counterintuitively, more student-reported caretaking hours were significantly and positively related to greater student-faculty interaction, more perceived institutional support, and more self-reported gains in knowledge and skills (Collins et al., in press, 2016). Conversely, among Indiana University students, caring for dependents was associated with 
lower odds of retention (Fiorini et al., 2014). While prior research results provide mixed evidence regarding the relationship between caring for dependents and student gains, it is an important variable to consider when examining URE outcomes at an HSI.

Socioeconomic status (SES) is hypothetically important to student gains from UREs. Not surprisingly, some studies have found lower SES among students to be associated with worse educational outcomes (Walpole, 2003; Engle and Tinto, 2008; Stuber, 2011). However, among Indiana University students, having an unmet financial need increased both the likelihood of first-year retention and 4-year graduation. While this seems counterintuitive, the authors asserted that students with unmet financial needs may value their educational experiences more than students from higher-SES backgrounds and may expend greater efforts to complete their university educations (Fiorini et al., 2014). This suggests that student participants of lower SES may stand to gain more than their higher-SES counterparts from UREs. Given the low SES of many students at MSIs, it is logical that providing more resources to URE program participants would result in greater gains. URE programs often provide resources such as monthly stipends, travel money for conference presentations, and funds for conducting the research project. While these factors are rarely examined, research has shown that providing resources (e.g., financial aid) to college students plays an important role in degree completion (Cerna et al., 2009).

Students' sex may also relate to gains from UREs, as female sex has been linked to better academic outcomes more generally (DeBerard et al., 2004; Conger and Long, 2010; DiPrete and Buchmann, 2013) and among Latinas specifically (Cole and Espinoza, 2008). In a study of summer URE participants, women reported greater learning gains than men (Lopatto, 2007), but men and women did not differ in terms of their intentions to continue their education (Lopatto, 2004). These findings suggest that student sex is an important variable to include in any study of student gains through UREs.

In sum, while prior studies have found the duration of the URE to positively predict student-reported gains from UREs, other potentially relevant influences on student gains in the context of UREs (e.g., mentoring quality, household income, and programmatic resources) remain largely unexamined. To address this, we examine the influence of multiple variables upon self-reported gains (i.e., thinking and working like a scientist, personal gains and gains in skill) among a sample of STEM undergraduate research program participants.

\section{MATERIALS AND METHODS Institutional Context}

UTEP provides an illustrative context to examine student gains associated with undergraduate research programs, especially among a majority URM study body. UTEP is one of the nation's leading contributors to diversity in higher education, specifically through the provision of educational opportunities for the rapidly growing albeit socially and economically disadvantaged U.S. Hispanic population. UTEP ranks second among all universities in the continental United States in the number of bachelor's degrees conferred to Hispanics (UTEP CIERP, 2014). Washington Monthly's 2013 rankings place UTEP as the seventh-best U.S. university overall, which is largely attributable to
UTEP's number one ranking in the "social mobility" category. According to institutional records, 57\% of enrolled undergraduates at UTEP from 2009 to 2013 were from the first generation in their families to attend college. UTEP has a Hispanic majority undergraduate student body. As of 2013, just under 20,000 undergraduate students were enrolled at UTEP; among those of known race/ethnicity, $87.3 \%$ of those were Hispanic, $2.8 \%$ were black (non-Hispanic), and $8.7 \%$ were white (non-Hispanic). UTEP is regarded as being highly supportive of student engagement. In Kuh et al.'s (2010) Student Success in College: Creating Conditions That Matter, UTEP was examined as a high-impact university in terms of student engagement, since it exhibited both higher than predicted graduation rates and higher than predicted scores on the National Survey of Student Engagement (NSSE).

\section{Participants}

An Institutional Review Board-approved structured survey (UTEP IRB No. 503441-1) based largely on the Undergraduate Research Student Self-Assessment (URSSA) and the NSSE was administered to participants using Qualtrics Survey Software. The URSSA instrument evaluates student outcomes of UREs. The URSSA instrument has been repeatedly tested, and the validity and reliability of the items within the instrument have been continuously verified (e.g., Weston and Laursen, 2015). Through the College Student Report survey instrument, the NSSE examines students' participation in programs and activities that institutions provide for their learning and personal development; the survey items can be used to obtain reliable estimates of how undergraduates spend their time and what they gain from attending college (NSSE, 2015). Using these valid and reliable measures allows for comparison of the outcomes of students in our study to outcomes measured in the same way in other student populations. The general aim of our survey was to collect information on undergraduate research program participants at UTEP from a variety of different programs in order to generally assess current program strengths and future needs.

The survey was distributed to students who were enrolled in an undergraduate research program at the time of the survey (the end of the Fall 2013 semester) and to students who had been involved in an undergraduate research program within the past 5 years (2009-2013), including those who had already graduated from the university. All students who were solicited had participated in their programs for a minimum of one summer or one semester. The names of the 408 students meeting those criteria were obtained from program directors of 10 programs at UTEP. These 10 programs included MARC (Minority Access to Research Careers), RISE (Research Initiatives for Scientific Enhancement), BRIDGES (Bridges to the Baccalaureate Program), SMARTS (Student Mentoring to Achieve Retention: Triads in Science), LSAMP (Louis Stokes Alliance for Minority Participation), COURI (Campus Office for Undergraduate Research Initiatives), STEM-RTI (STEM Research Teaching Integration), UPBIT (Undergraduate Participation in Bioinformatics Training), SMART:MIND (Summer Mentoring and Research Training: Methods in the Neuroscience of Drug-abuse), and the provost office's summer research assistant program. These programs vary in the duration of engagement with trainees, lasting between a minimum of one 
summer to a maximum of several years with yearly reappointment. Many of these programs are supported by either the National Institutes of Health (NIH) or the National Science Foundation.

In terms of sample demographics, $89.4 \%$ of respondents identified themselves as Latino/a, Hispanic, or of Spanish origin, which closely reflects UTEP's demographics. Of the respondents, 70\% reported speaking a language other than English at home and $59.4 \%$ were female. Nearly $40 \%$ of the respondents had graduated at the time of the survey, while the other $60 \%$ were still enrolled as undergraduates.

\section{Data Collection}

The survey was active for 4 weeks (beginning in the middle of November 2013 and ending in the middle of December 2013). Our strategies to enhance the response rate involved sending a prenotification message via email to invite participation in the study and sending three follow-up email reminders to nonrespondents (Manfreda and Vehovar, 2008). In addition, two waves of postcards were sent to permanent addresses of the students. Participants were awarded with a \$10 gift card to incentivize survey completion. The response rate was 53\%, and a total of 227 individuals completed the survey.

\section{Variables}

We used three URSSA constructs as dependent variables: 1) thinking and working like a scientist, 2) personal gains, and 3) gains in knowledge and skills (URSSA, 2009). These reported gains relate to students' most recent undergraduate research program experience. 1) "Thinking and working like a scientist" refers specifically to student reports of growth in applying scientific knowledge and skills, understanding the scientific research process, and improving their intellectual understanding of the field. 2) "Personal gains" relates to student reports of improvement in comfort and ability working within the scientific field. 3) "Gains in knowledge and skills" measures student reports of acquisition of new skills and knowledge within the field and expansion of their existing knowledge outside the field. As per URSSA, the gains scales items on the survey were rated on a five-point Likert scale ranging from $1=$ no gain to $5=$ a great gain. The three composite-gains items were created by taking the mean response of the specific questions under each gains item. Cronbach's alpha scores for each construct revealed that they were reliable. The Cronbach's alpha scores were 0.923 for thinking and working like a scientist, 0.929 for personal gains, and 0.914 for gains in knowledge and skills. Table 1 reports the specific survey questions used for each gains measure and the justifications for using each selected gains measure.

We used eight independent variables in our analysis that are relevant to each student's most recent research program experience (as it is possible for a student to have taken part in more than one program sequentially) along with two control variables. 1) "Months in a research experience" was calculated by converting the reported semesters and summers spent in their most recent research program into total months. 2) The "quality of mentoring" variable was rated on a four-point Likert scale ( 1 = poor, 2 = fair, 3 = good, and 4 = excellent) for the most recent research program experience. 3) Being Latino/a or Hispanic was coded as 1 for yes and 0 for no. 4) "Speaking a language other than English at home" was coded as 1 for yes and 0 for no. 5) "Providing for children or dependents" was calculated by taking the midpoint of the hours reported doing that activity each week during their most recent research program, for example, if a student reported spending 26-30 h providing care, the recoded variable would reflect $28 \mathrm{~h}$. 6) Income was measured on a nine-point scale ranging from 1 (less than $\$ 10,000$ per year) to 9 (more than $\$ 250,000$ per year). 7) Sex was coded 1 for male and 0 for female. 8) "Resources received" as part of the student's most recent research program was created based on summing responses from a checklist of resources developed based on a review of what each program provided.

The study used two control variables. "Having already graduated" at the time of the survey was coded as 1 for yes and 0 for no. "Participation in more than 1 program" was created by summing responses from a checklist of programs students could have participated in; students who had been in two or more programs were then recoded as 1 , and students who had been in 1 program were recoded to 0 .

Table 2 reports the descriptive statistics for the thirteen variables. Students on average reported approximately "good gain" on the three gains measures (with the average score ranging from 4.09 to 4.27 out of 5). Approximately $11.6 \%$ of students participated in their research program for one summer, $36.6 \%$ participated in their research program for 3-12 mo, and $49.1 \%$ did research through their program for more than $12 \mathrm{mo}$. The mean length of a research experience was nearly 15 mo. The mean student ranking for the quality of research mentor was 3.21 on a four-point scale. Thirty percent of the students reported providing for children or dependents, and, across the entire sample, the mean time spent doing this was 6-10 h each week. The median value for household income reported was 3 , which is from $\$ 30,000$ to just less than $\$ 40,000$ (median value not shown in Table 2). The mean number of reported resources received by students was 4.1 , with the most commonly received items being stipends to support living expenses followed by supplies to conduct research, equipment to conduct research, and workshops for professional development. Approximately $24.7 \%$ of students had participated in more than one research program.

\section{Analytical Methods}

Generalized linear models (GzLMs) were used to examine relationships between the independent variables and the three different gains items. GzLMs support analysis of nonnormal distributions and employ multiple link functions (Nelder and Wedderburn, 1972). On the basis of visual inspection of the histogram of our dependent variable (unpublished data), we ran the GzLMs with six different specifications: inverse Gaussian distribution with log and identity link functions, gamma distribution with log and identity link functions, and normal distribution with log and identity link functions. The identity link function means the dependent variable is predicted directly and is not transformed, while the log link function models the natural log of the dependent variable (Garson, 2012). We selected normal distribution with identity link function for the three final GzLMs, since these specifications yielded the lowest Akaike information criterion (AIC) values for each of the models (see Table 3). A normal distribution with identity link function GzLM is equivalent to an ordinary least-squares (OLS) regression model, which is, in fact, a special case of GzLM. Findings for a normal distribution with 


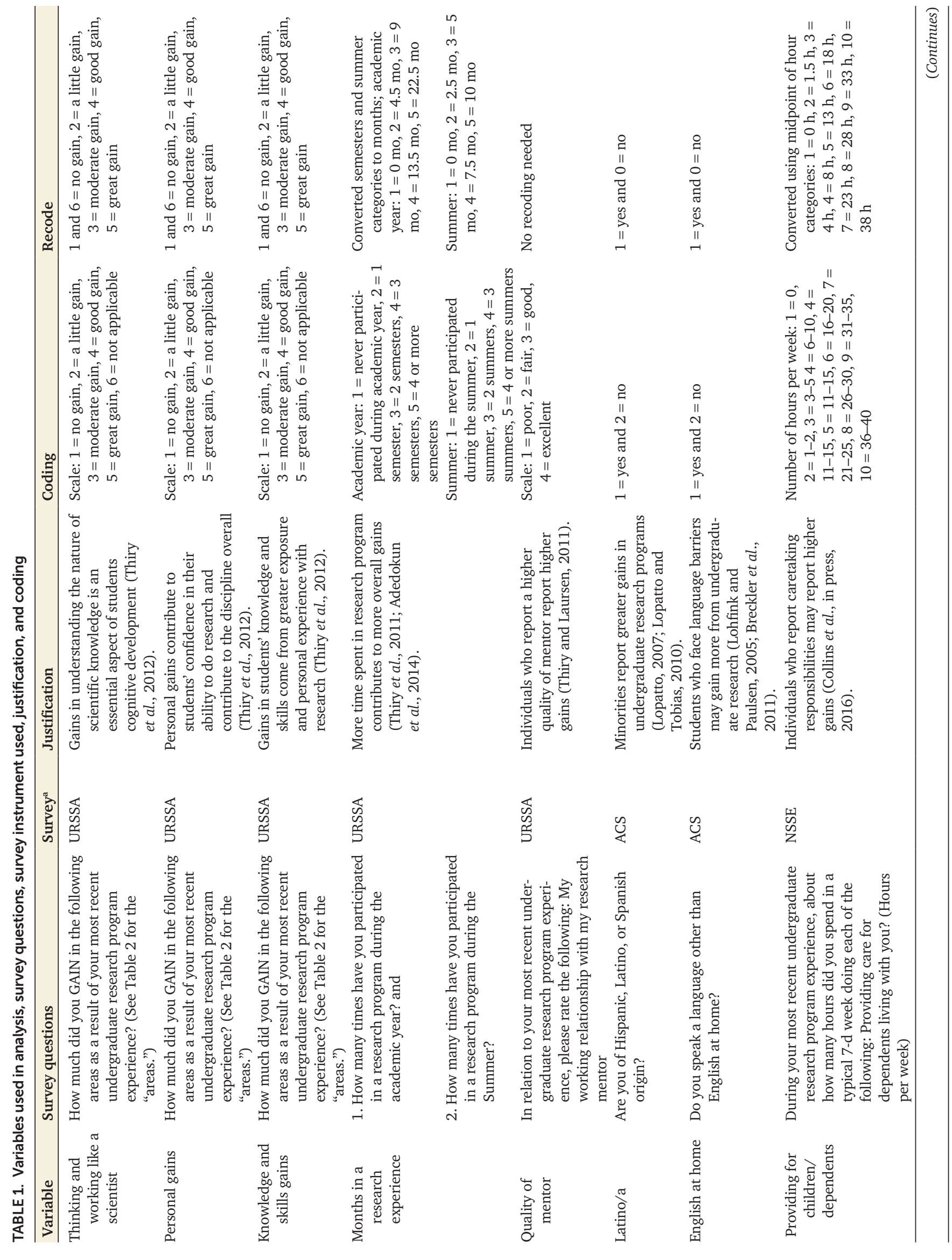




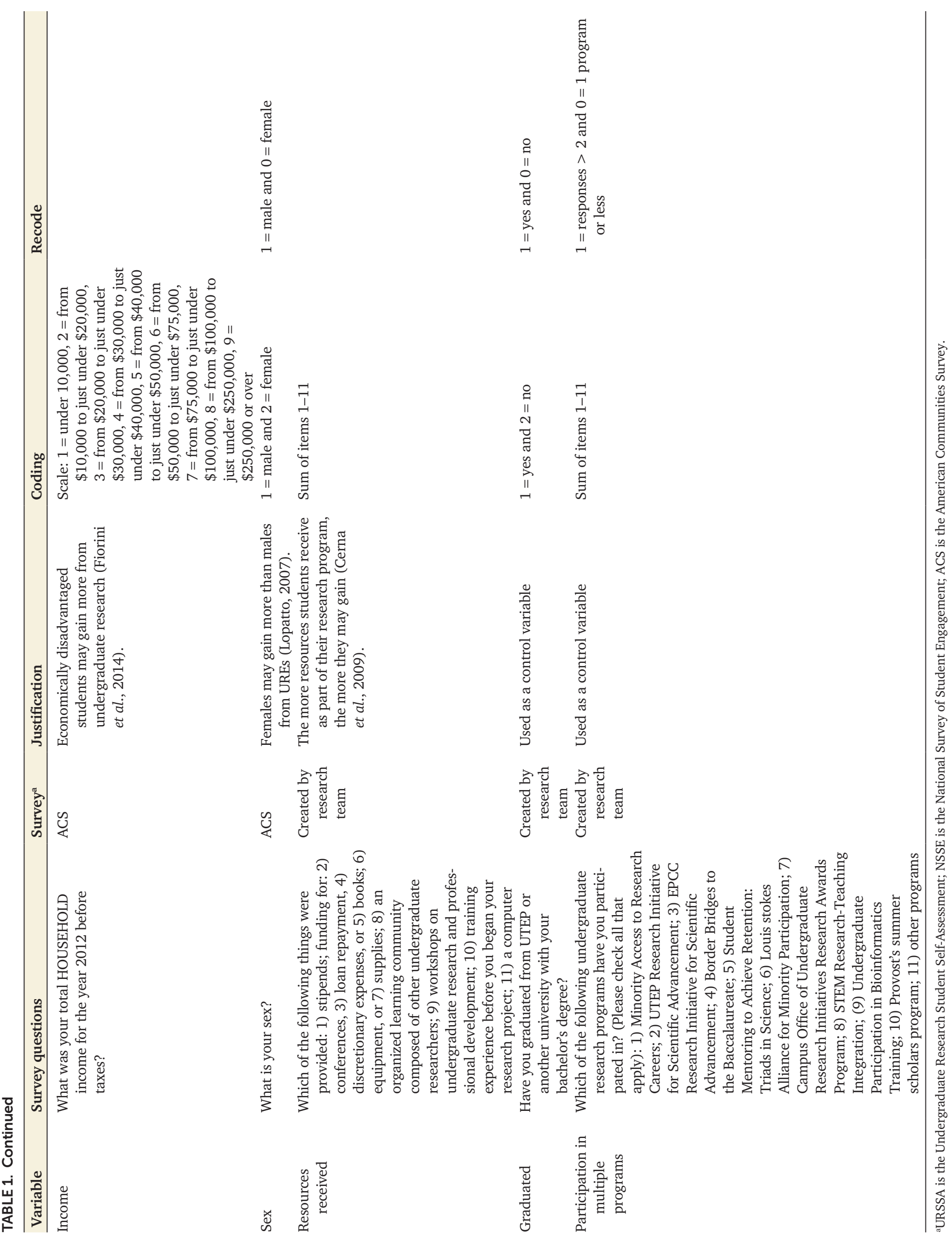


TABLE 2. Descriptive statistics for all analysis variables including those variables comprising the composite indicators

\begin{tabular}{|c|c|c|c|c|c|c|}
\hline Continuous variables & $n$ & Minimum & Maximum & Mean & SD & $\%$ Missing \\
\hline Thinking and working like a scientist & 211 & 1 & 5 & 4.19 & 0.818 & 7 \\
\hline - Analyzing data for patterns & 214 & 1 & 5 & 4.05 & 1.125 & 5.7 \\
\hline - Figuring out the next step in a research project & 214 & 1 & 5 & 4.23 & 0.959 & 5.7 \\
\hline - Problem solving in general & 214 & 1 & 5 & 4.28 & 0.901 & 5.7 \\
\hline - Formulating a research question that could be answered with data & 214 & 1 & 5 & 4.09 & 1.091 & 5.7 \\
\hline - Identifying limitations of research methods and designs & 214 & 1 & 5 & 4.11 & 1.071 & 5.7 \\
\hline - Understanding the theory and concepts guiding my research project & 212 & 1 & 5 & 4.27 & 0.939 & 6.6 \\
\hline - Understanding the connections among scientific disciplines & 214 & 1 & 5 & 4.18 & 1.082 & 5.7 \\
\hline - Understanding the relevance of research to my course work & 213 & 1 & 5 & 4.32 & 1.037 & 6.2 \\
\hline Personal gains & 210 & 1 & 5 & 4.28 & 0.836 & 7.5 \\
\hline - Confidence in my ability to contribute to science & 213 & 1 & 5 & 4.07 & 1.086 & 6.2 \\
\hline - Comfort in discussing scientific concepts with others & 213 & 1 & 5 & 4.15 & 0.998 & 6.2 \\
\hline - Comfort in working collaboratively with others & 212 & 1 & 5 & 4.31 & 1.024 & 6.6 \\
\hline - Confidence in my ability to do well in future science courses & 213 & 1 & 5 & 4.23 & 1.090 & 6.2 \\
\hline - Ability to work independently & 212 & 1 & 5 & 4.40 & 0.956 & 6.6 \\
\hline - Developing patience with the slow pace of research & 213 & 1 & 5 & 4.24 & 1.097 & 6.2 \\
\hline - Understanding what everyday research work is like & 213 & 1 & 5 & 4.49 & 0.877 & 6.2 \\
\hline - Taking greater care in conducting research procedures & 212 & 1 & 5 & 4.32 & 1.054 & 6.6 \\
\hline Gains in skills & 206 & 1 & 5 & 4.03 & 0.811 & 9.3 \\
\hline - Writing scientific reports or papers & 213 & 1 & 5 & 4.10 & 1.081 & 6.2 \\
\hline - Making oral presentations & 212 & 1 & 5 & 4.21 & 1.082 & 6.6 \\
\hline - Defending an argument when asked questions & 212 & 1 & 5 & 3.96 & 1.080 & 6.6 \\
\hline - Explaining my project to people outside my field & 212 & 1 & 5 & 4.28 & 0.975 & 6.6 \\
\hline - Preparing a scientific poster & 213 & 1 & 5 & 4.13 & 1.248 & 6.2 \\
\hline - Using statistics to analyze data & 213 & 1 & 5 & 3.71 & 1.331 & 6.2 \\
\hline - Working with computers & 212 & 1 & 5 & 3.86 & 1.249 & 6.6 \\
\hline - Understanding journal articles & 212 & 1 & 5 & 4.26 & 0.951 & 6.6 \\
\hline - Conducting database or Internet searches & 213 & 1 & 5 & 4.16 & 1.018 & 6.2 \\
\hline - Managing my time & 212 & 1 & 5 & 4.10 & 1.006 & 6.6 \\
\hline $\begin{array}{l}\text { - Using conventional methods, techniques, and technologies to conduct } \\
\text { research in my field }\end{array}$ & 211 & 1 & 5 & 4.10 & 1.108 & 7 \\
\hline Months in a research experience & 216 & 0 & 31.5 & 14.77 & 9.927 & 4.8 \\
\hline Quality of mentor & 212 & 1 & 4 & 3.21 & 0.912 & 6.6 \\
\hline Providing for children/dependents & 216 & 0 & 38 & 4.65 & 10.243 & 4.8 \\
\hline Income & 203 & 1 & 9 & 3.81 & 2.114 & 10.6 \\
\hline Resources received & 200 & 0 & 10 & 4.10 & 2.820 & 27 \\
\hline Dichotomous variables & $n$ & \multicolumn{2}{|c|}{ Yes } & \multicolumn{2}{|c|}{ No } & $\%$ Missing \\
\hline Latino/a & 227 & \multicolumn{2}{|c|}{203} & \multicolumn{2}{|l|}{24} & 0 \\
\hline English at home & 212 & \multicolumn{2}{|c|}{149} & \multicolumn{2}{|l|}{63} & 6.6 \\
\hline Sex & 227 & \multicolumn{2}{|c|}{92 (male) } & \multicolumn{2}{|c|}{135 (female) } & 0 \\
\hline Graduated & 216 & \multicolumn{2}{|c|}{85} & \multicolumn{2}{|c|}{131} & 4.8 \\
\hline Participation in more than one program & 227 & \multicolumn{2}{|c|}{56} & \multicolumn{2}{|l|}{171} & 0 \\
\hline
\end{tabular}

identity link function GzLM can be interpreted as though the model was an OLS regression model. Our dependent and independent variables are normally distributed, based on skewness and kurtosis statistics. Because AIC values for the normal distribution with log link function models were close to the normal distribution with identity link function models, we also specified and examined the three GzLMs using normal distribution with log link function; findings between the two sets of models fully agreed in terms of the direction and signif- icance of relationships between the independent and dependent variables. We tested for possible multicollinearity among the analysis variables included in each GzLM. According to variance inflation factor, tolerance, and condition index criteria (Belsley et al., 1980), inferences from GzLM results were not affected by multicollinearity problems.

Multiple imputation (MI) techniques address potential bias associated with missing data in statistical analysis. They involve creating multiple sets of values for missing observations using a 
TABLE 3. Model fit statistics (i.e., AIC scores) for the six specifications considered for the GzLM models

\begin{tabular}{lccc}
\hline & $\begin{array}{c}\text { A. Thinking and working } \\
\text { like a scientist }\end{array}$ & B. Personal gains & $\begin{array}{c}\text { C. Knowledge and } \\
\text { skills gains }\end{array}$ \\
\hline Inverse Gaussian with log link & 489.221 & 1299.376 & 1363.404 \\
Inverse Gaussian with identity link & 510.832 & 1294.638 & 1430.123 \\
Gamma with log link & 453.188 & 1250.250 & 1335.108 \\
Gamma with identity link & 449.235 & 1245.456 & 1332.247 \\
Normal with log link & 403.180 & 1185.805 & 1298.929 \\
Normal with identity link & 399.729 & 1181.255 & 1296.610 \\
\hline
\end{tabular}

${ }^{\text {aResults reported in Table } 4 .}$

regression-based approach. MI is used to avoid the bias that can occur when missing values are not missing completely at random (Penn, 2007) and is appropriate for self-reported survey data (Enders, 2010). We used MI to impute the missing values of all analysis variables before running the GzLM. Twenty imputed data sets were specified, which is a current "rule of thumb" in MI, as it maximizes power (as opposed to using 3-5 data sets, which used to be the convention) and improves the validity of multiparameter significance tests, and 200 between-imputation iterations were used to ensure the resulting imputations were independent of each other (Enders, 2010). MI techniques appropriately adjust standard errors for missing data as part of the pooling phase (Enders, 2010), wherein separate model results for each of the 20 imputed data sets were combined into pooled model results (which we report here).

MI was used for the GzLM, while univariate analyses (i.e., descriptive statistics) utilized original data only. Analyses of the MI data sets did not change the significance or direction of any of relationships between the independent and dependent variables in the pooled GzLM results, as compared with model results from analyses employing the original data only. Table 2 displays the percent missing for each analysis variable. The nondichotomous independent variables, including those based on ordinal measures (e.g., quality of mentoring), were standardized and analyzed as continuous predictors in the GzLM. This approach is considered a best practice in MI when imputing missing data and estimating model parameters, since rounding off imputed values based on discrete categorical specifications has been shown to produce more biased parameter estimates in analysis models (Horton et al., 2003; Allison, 2005; Enders, 2010; Rodwell et al., 2014). IBM SPSS (version 21) was used to conduct all analyses.

\section{RESULTS}

Table 4A reports pooled results for the model predicting gains in thinking and working like a scientist. In this model, both having higher-quality mentoring and spending more months in a research experience were significantly associated $(p<0.05)$ with greater self-reported gains. Receiving more resources through the program and spending more time providing for children or dependents were also significantly associated $(p<0.05)$ with greater self-reported gains in thinking and working like a scientist. Income, speaking a language other than English at home, having already graduated at the time of the survey, being Latino/a, sex, and engagement in more than one program were not found to be significant predictors of self-reported gains in thinking and working like a scientist.

Table 4B reports results for the model predicting self-reported personal gains. Within this model, having higher-quality mentoring as well as spending more months in a research experience were significantly associated $(p<0.05)$ with greater self-reported gains. Acquiring more resources through the program and spending more time providing for children or dependents were significantly associated $(p<0.05)$ with greater self-reported personal gains, as was being Latino/a. However, speaking a language other than English at home, having already graduated at the time of the survey, sex, and participation in more than one program were not significant predictors of self-reported personal gains.

TABLE 4. Results of generalized linear models predicting student gains in three areas $(n=227)^{\text {a }}$

\begin{tabular}{|c|c|c|c|c|c|c|c|c|c|}
\hline \multirow[b]{2}{*}{ Independent variables } & \multicolumn{3}{|c|}{$\begin{array}{c}\text { A. Thinking and working } \\
\text { like a scientist }\end{array}$} & \multicolumn{3}{|c|}{ B. Personal gains } & \multicolumn{3}{|c|}{$\begin{array}{l}\text { C. Gains in knowledge } \\
\text { and skills }\end{array}$} \\
\hline & B & SE & $p$ Value & B & SE & $p$ Value & B & SE & $p$ Value \\
\hline Months in a research experience & 0.012 & 0.0053 & 0.019 & 0.011 & 0.0054 & 0.034 & 0.008 & 0.0054 & 0.117 \\
\hline Quality of mentor & 0.333 & 0.0527 & $<0.001$ & 0.343 & 0.0533 & $<0.001$ & 0.248 & 0.0528 & $<0.001$ \\
\hline Latino/a & 0.214 & 0.1631 & 0.189 & 0.348 & 0.1646 & 0.035 & 0.110 & 0.1659 & 0.507 \\
\hline English at home & -0.025 & 0.1099 & 0.817 & -0.009 & 0.1110 & 0.939 & 0.079 & 0.1119 & 0.483 \\
\hline Providing for children/dependents & 0.011 & 0.0048 & 0.023 & 0.010 & 0.0048 & 0.037 & 0.014 & 0.0048 & 0.005 \\
\hline Income & -0.029 & 0.0233 & 0.213 & -0.034 & 0.0237 & 0.152 & -0.033 & 0.0237 & 0.158 \\
\hline Sex & 0.056 & 0.0966 & 0.562 & -0.036 & 0.0976 & 0.714 & 0.023 & 0.0978 & 0.810 \\
\hline Resources received & 0.093 & 0.0202 & $<0.001$ & 0.082 & 0.0203 & $<0.001$ & 0.091 & 0.0204 & $<0.001$ \\
\hline Graduated & -0.105 & 0.1088 & 0.333 & -0.045 & 0.1090 & 0.683 & 0.058 & 0.1098 & 0.596 \\
\hline Participation in multiple programs & -0.124 & 0.1130 & 0.273 & -0.009 & 0.1141 & 0.939 & -0.026 & 0.1147 & 0.817 \\
\hline
\end{tabular}

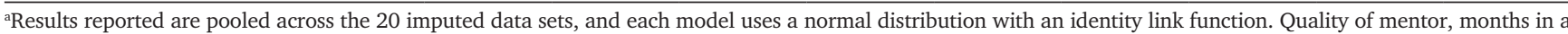
research experience, resources received as part of research program, providing for children/dependents, and income were included as standardized variables. 
Results for the model predicting gains in knowledge and skills are presented in Table 4C. As with the other two GzLMs, having higher-quality mentoring was significantly associated $(p<0.05)$ with greater self-reported gains, but spending more months in a research experience was not significant, although the effect was positive. Receiving more resources through the program and spending more time providing for children or dependents were significantly associated $(p<0.05)$ with greater self-reported gains in knowledge and skills. The rest of the variables were not statistically significant.

\section{DISCUSSION}

Most of the literature on undergraduate research programs has focused on the effect of time on student gains; however, the results of this study indicate that quality is more important when predicting student gains and fostering the development of knowledge and skills. The quality of mentoring was a significant predictor of student gains across all three GzLMs. Comparing the parameter estimates (Table 4B), the effect size for quality of mentoring is more significant and nearly triple the effect size for months in a research experience in the thinking like a scientist, personal gains, and gains in knowledge and skills GzLMs. ${ }^{1}$ Our findings in regard to mentoring quality have not been found in previous studies of undergraduate research training. Spending more months in a faculty-mentored research program was significantly and positively related to personal gains and thinking and working like a scientist, but not to knowledge and skills gains. Thus, the length of the research experience may be most important for psychosocial gains, including the formation of a science identity, which is in line with findings from previous studies (Thiry et al., 2011, 2012). In contrast, results suggest that gains in knowledge and skills may be more closely linked to quality mentorship, and that such gains may accrue over relatively short time frames through focused, high-quality interaction and engagement with a faculty mentor. Our results indicate that the duration of engagement in faculty-mentored research and the quality of mentorship each contribute independently to student gains, ${ }^{2}$ but that high-quality mentoring may be more important on the whole than having a URE of long duration. In practical terms, this suggests that students may stand to gain in the three areas measured here from relatively short-duration UREs, assuming that they engage in high-quality interactions with their mentor. Our results also indicate that undergraduate research programs might generate greater impacts on student development by providing training to faculty mentors in the practice of undergraduate student mentoring.

In terms of the other factors considered, there were several notable findings. Spending more hours caring for children or dependents was found to be a significant positive predictor of gains in all three GzLMs. We believe that this may be attributed to students with family responsibilities prioritizing their time

\footnotetext{
${ }^{1}$ We also examined time as a nonlinear predictor through the use of a quadratic term in our three GzLM models (unpublished data). The effect of time when considered this way did not approach statistical significance, while quality retained its significance in all three models, suggesting that quality was more important in this analysis.

${ }^{2}$ The effect of quality of mentorship was not moderated by time in the program, as their interaction term did not approach statistical significance in any of the three GzLM models (unpublished data).
}

differently than their peers who do not have this extra obligation. These students have limited amounts of time and may invest more energy into their time spent doing undergraduate research and therefore get more out of the experience than students who do not report caretaking obligations. This finding is not unique to these research participants; prior research on graduating seniors at UTEP showed that more student-reported caretaking obligations significantly and positively predicted more student-faculty interaction, more perceived institutional support, more self-reported gains in knowledge and skills, and greater overall satisfaction with the UTEP experience (Collins et al., in press, 2016).

Providing more resources as part of research programs was also associated with significantly greater gains in all three areas. This suggests that programs that provide more resources (e.g., money to support travel to conferences, repayment of student loans, funds to support living expenses, equipment for research, and skills-building opportunities like workshops and seminars) are highly beneficial in terms of student gains, even when accounting for students' household income. Future research should disentangle which types of resources would be most beneficial to provide within URE programs. Being Latino/a was significantly associated with greater self-reported personal gains. Being Latino/a was not significant in the other two GzLMs, but the effect was positive, which suggests that Latino/a students may gain more from participation in faculty-mentored UREs than non-Hispanics. The small numbers of non-Latino/a students in the sample may have increased our SE and reduced our ability to find a statistically significant association. Our results suggest that Hispanic students may gain more than non-Hispanic students from participation in undergraduate research programs at this HSI. This finding is in line with previous studies finding that URM students benefit disproportionately from UREs (Lopatto, 2007; Russell et al., 2007; Jones et al., 2010; Eagan et al., 2013). Student sex, income, participating in more than one program, and speaking a language other than English at home were not found to be significant in any of the GzLMs, indicating they are not important correlates of self-reported gains.

Future research would be advanced through the use of a multidimensional scale to measure the quality of research mentorship. In past qualitative research, students have been asked to describe mentor quality in ideal terms (Ishiyama, 2007; Thiry et al., 2011). Their assessments shed light on what students are likely considering when asked to rate the quality of the mentorship they have received. Undergraduate students defined a quality mentor as one who regularly interacts with them, helps with their understanding of the values and norms of their profession, and provides intellectual as well as personal or emotional support (Thiry et al., 2011). An examination of students in the McNair postbaccalaureate program found that black students were more likely than white students to describe a good mentor as one who is personally supportive (Ishiyama, 2007). When defining the "mentor concept" based on a thorough review of the literature, Crisp and Cruz (2009) assert that academic mentoring involves four domains: psychological and emotional support, support for setting goals and choosing a career path, academic subject knowledge support aimed at advancing a student's knowledge of his or her chosen field, and specification of a role model 
(Crisp and Cruz, 2009). This qualitative work supports the assertion that a multidimensional scale is needed.

While our reliance on URSSA meant we used a unidimensional scale, multidimensional scales to assess URE mentor quality are available. For example, the Mentoring Competency Assessment (MCA), developed by researchers the University of Wisconsin-Madison, enables research mentees to evaluate six competencies of their mentors. This instrument consists of 26-items which are rated on a seven-point Likert-type scale, and it addresses the following domains: maintaining effective communication, aligning expectations, assessing understanding, addressing diversity, fostering independence, and promoting professional development (Fleming et al., 2013). Because there are versions available for the mentee and mentor, this instrument can also be used to identify areas in which mentor and mentee assessments diverge, which would provide information useful for faculty development interventions (Pfund et al., 2014). The use of a multidimensional scale designed to measure more aspects of the student-mentor relationship would provide an improved basis for analyzing the role of mentoring quality in student development via undergraduate research participation.

A second limitation is our examination of only the most recent research program experiences of participants. However, only one-quarter of students had participated in more than one program, and this variable was not a significant predictor of self-reported gains in any of the three GzLMs. We also assumed, by summing up the number of resources provided by the students' programs, that each resource was equally important to students' self-reported gains, when it may be the case that some resources are more valuable than others.

Furthermore, our analysis is based on student self-reports for all gains items. Self-reports may be subject to social desirability responses. However, there is evidence that self-report measures are less susceptible to this type of response when the accuracy of the item responses is verifiable (Chan, 2009). Self-reports can also suffer from recall bias (Hassan, 2006). When studying something as subjective as one's own personal gains, self-reports are the best source of data, since they are related to how one feels about oneself. In terms of knowledge, skills, and science gains, there are limitations to self-reported measures, as documented by recent studies (Gordon et al., 2008; Bowman, 2010, 2011). Those studies suggest that self-report-based gains measures should not be used as simple proxies for actual student learning. We believe that it is still important to examine self-reported gains in the context of UREs. The standardized test-based measures used to assess learning in prior studies are not designed to gauge objective growth in highly specialized research skills/techniques that typically define URE experiences; but this growth can be captured by the URSSA gains scales. The self-reported gains we examine may reflect the acquisition of highly specialized research skills not readily captured by other, more objective measures, although no extant studies substantiate (or refute) that claim.

\section{CONCLUSION}

Our results suggest several practical implications when designing and implementing undergraduate research programs. More training for research mentors may improve the quality of the experiences they provide for students within undergraduate research programs. Previous studies have demonstrated the benefits of targeted training to improve research-mentoring practices among faculty members (Pfund et al., 2006, 2013; Balster et al., 2010). For example, research employing the MCA scale described above has demonstrated that, after mentors complete a structured mentoring curriculum, their mentees report an improvement in mentor competency (Pfund et al., 2014). Mentors who take part in training are usually satisfied with the experience; they self-report measurable skills gains as well as positive behavioral changes (Pfund et al., 2013). For example, trained mentors are significantly more likely than untrained mentors to discuss their expectations with their undergraduate research protégés, to consider issues of diversity, and to discuss mentoring with peers and faculty members (Pfund et al., 2006).

Training opportunities for mentors are accessible. For example, Optimizing the Practice of Mentoring is a free online curriculum developed by the Clinical and Translational Science Institute at the University of Minnesota to prepare faculty in higher education to be effective research mentors (www.ctsi.umn.edu/education-and-training/mentoring/ mentor-training). Entering Mentoring is a curriculum developed by a team from the University of Wisconsin-Madison for use across STEM disciplines. This program helps mentors explore issues that affect their research-mentoring relationships and enables them to practice more reflective and effective mentorship. These materials are available online at no cost (www.researchmentortraining.org). The National Research Mentoring Network (NRMN) was funded by NIH beginning in 2014 and has developed best practices for mentoring. The NRMN also provides training opportunities for mentors, mentee-mentor matching, and networking and professional development opportunities for mentors (http:// nrmnet.net).

Additionally, we found that students who received more resources as part of their program reported greater gains. This suggests that providing resources such as tuition reimbursement, living expense stipends, and supplies such as computers would improve outcomes for students engaged in UREs, especially for those who are economically disadvantaged. There are many research programs available to students currently, but without all the necessary components, students may not be gaining as much from these programs as they could be.

Overall, the quality of mentoring received by students and the months that the students spent in their research experience both matter in predicting student gains. Our results indicate, however, that quality may be a more important predictor than quantity. Length of research experience may influence gains from UREs, but not all time spent in a research program is productive or contributes to student development. Raising the quality of mentorship within research programs will enable students to benefit from both longer experiences that begin earlier in their undergraduate careers and short-duration research engagement, for example, summer experiences. Mentoring training for faculty members within undergraduate research programs should be a top priority to increase the quality of mentoring provided to student participants and, in turn, to improve outcomes defined in terms of student gains. 


\section{REFERENCES}

Adedokun OA, Parker LC, Childress A, Burgess W, Adams R, Agnew CR, Leary J, Knapp D, Shields C, Lelievre S, et al. (2014). Effect of time on perceived gains from an undergraduate research program. CBE Life Sci Educ 13, 139-148.

Allison PD (2005). Imputation of categorical variables with PROC MI. In: Proceedings of the Thirtieth Annual SAS Users Group International Conference, Cary, NC: SAS Institute, paper 113-30

Balster N, Pfund C, Rediske R, Branchaw J (2010). Entering research: a course that creates community and structure for beginning undergraduate researchers in the STEM disciplines. CBE Life Sci Educ 9, 108-118.

Bauer KW, Bennett JS (2003). Alumni perceptions used to assess undergraduate research experience. J High Educ 74, 210-230.

Belsley DA, Kuh E, Welsch RE (1980). Regression Diagnostics: Identifying Influential Data and Sources of Collinearity, Hoboken, NJ: Wiley.

Bowman NA (2010). Can 1st-year college students accurately report their learning and development? Am Educ Res J 47, 466-496.

Bowman NA (2011). Examining systematic errors in predictors of college student self-reported gains. New Directions for Res 2011, 7-19.

Breckler J, Teoh CS, Role K (2011). Academic performance and learning style self-predictions by second language students in an introductory biology course. J Scholarsh Teach Learn 11(4), 26-43.

Campbell TA, Campbell DE (1997). Faculty/student mentor program: effects on academic performance and retention. Res High Educ 38, 727-742

Cerna OS, Pérez PP, Sáenz VB (2009). Examining the precollege attributes and values of Latina/o bachelor's degree attainers. J Hispanic High Educ 8, 130-157.

Chan D (2009). So why ask me? Are self-report data really that bad? In: Statistical and Methodological Myths and Urban Legends: Doctrine Verity and Fable in the Organizational and Social Sciences, ed. CE Lance and RJ Vandenberg, New York: Taylor \& Francis, 309-336.

Cole D, Espinoza A (2008). Examining the academic success of Latino students in science technology engineering and mathematics (STEM) majors. J Coll Stud Dev 49, 285-300.

Collins TW, Grineski SE, Shenberger J, Morales DX, Morera OF, Echegoyen L (2016). Undergraduate research participation improves educational outcomes. J Coll Stud Dev (in press).

Conger D, Long MC (2010). Why are men falling behind? Gender gaps in college performance and persistence. Ann Am Acad Pol Soc Sci 627, 184-214.

Crisp G (2010). The impact of mentoring on the success of community college students. Rev High Ed 34, 39-60.

Crisp G, Cruz I (2009). Mentoring college students: a critical review of the literature between 1990 and 2007. Res High Educ 50, 525-545.

Crisp G, Nora A, Taggart A (2009). Student characteristics, pre-college, college, and environmental factors as predictors of majoring in and earning a STEM degree: an analysis of students attending a Hispanic serving institution. Am Educ Res J 46, 924-942.

DeBerard MS, Spielmans Gl, Julka DL (2004). Predictors of academic achievement and retention among college freshmen: a longitudinal study. Coll Stud J 38, 66.

DiPrete TA, Buchmann C (2013). The Rise of Women: The Growing Gender Gap in Education and What It Means for American Schools, New York: Russell Sage Foundation.

Eagan MK, Hurtado S, Chang MJ, Garcia GA, Herrera FA, Garibay JC (2013). Making a difference in science education the impact of undergraduate research programs. Am Educ Res J 50, 683-713.

Enders CK (2010). Applied Missing Data Analysis, New York: Guilford Press

Engle J, Tinto V (2008). Moving Beyond Access: College Success for Low-Income, First-Generation Students, Washington, DC: Pell Institute for the Study of Opportunity in Higher Education.

Fiorini S, Liu T, Shepard L, Ouimet J (2014). Using NSSE to understand student success: a multi-year analysis. Presented at the Annual Conference of the Indiana Association for Institutional Research, Indianapolis, IN, 5 November 2014

Fleming M, House MS, Shewakramani MV, Yu L, Garbutt J, McGee R, Kroenke K, Abedin MZ, Rubio DM (2013). The mentoring competency assessment: validation of a new instrument to evaluate skills of research mentors. Acad Med 88, 1002

Garson G (2012). Generalized Linear Models and Generalized Estimating Equations, Asheboro, NC: Statistical Associates

Gordon J, Ludlum J, Hoey JJ (2008). Validating NSSE against student outcomes: are they related? Res High Educ 49, 19-39.

Hassan E (2006). Recall bias can be a threat to retrospective and prospective research designs. Internet J Epidemiol 3, 339-412.

Horton NJ, Lipsitz SR, Parzen M (2003). A potential for bias when rounding in multiple imputation. Am Stat 57, 229-232.

Hunter AB, Laursen SL, Seymour E (2007). Becoming a scientist: the role of undergraduate research in students' cognitive, personal, and professional development. Sci Educ 91, 36-74.

Ishiyama J (2007). Expectations and perceptions of undergraduate research mentoring: comparing first generation, low income white/Caucasian and African American students. Coll Stud J 41, 540.

Jacobi $M$ (1991). Mentoring and undergraduate academic success: a literature review. Rev Educ Res 61, 505-532.

Jones MT, Barlow AE, Villarejo M (2010). Importance of undergraduate research for minority persistence and achievement in biology. $\mathrm{J}$ High Educ 81, 82-115.

Kuh GD (2008). High-Impact Educational Practices: What They Are, Who Has Access to Them, and Why They Matter, Washington, DC: Association of American Colleges and Universities

Kuh GD, Kinzie J, Schuh JH, Whitt EJ (2010). Student Success in College: Creating Conditions That Matter, Hoboken, NJ: Wiley.

Laursen S, Hunter AB, Seymour E, Thiry H, Melton G (2010). Undergraduate Research in the Sciences: Engaging Students in Real Science, Hoboken NJ: Wiley.

Lohfink MM, Paulsen MB (2005). Comparing the determinants of persistence for first-generation and continuing-generation students. J Coll Stud Dev 46, 409-428.

Lopatto D (2004). Survey of undergraduate research experiences (SURE): first findings. Cell Biol Educ 3, 270-277.

Lopatto D (2007). Undergraduate research experiences support science career decisions and active learning. CBE Life Sci Educ 6, 297306

Lopatto D, Tobias S (2010). Science in Solution: The Impact of Undergradu ate Research on Student Learning. Washington, DC: Council on Undergraduate Research.

Manfreda K, Vehovar V (2008). Internet surveys. In: International Handbook of Surveys, ed. E Leeuw, J Hox, and D Dillman, CRC, New York: Taylor and Francis, 264-284.

National Survey of Student Engagement (2015). About NSSE, Bloomington Indiana University. http://nsse.indiana.edu/html/about.cfm.

Nelder JA, Whetterburn RWM (1972). Generalized linear models. J R Statist Soc, Ser A (Gen) 135, 370-384.

Paglis LL, Green SG, Bauer TN (2006). Does adviser mentoring add value? A longitudinal study of mentoring and doctoral student outcomes. Res High Educ 47, 451-476.

Penn DA (2007). Estimating missing values from the general social survey: an application of multiple imputation. Soc Sci Q 88, 573-584.

Pfund C, House SC, Asquith P, Fleming MF, Buhr KA, Burnham EL, Gilmore JM, Huskins WC, McGee R, Schurr K, et al. (2014). Training mentors of clinical and translational research scholars: a randomized controlled trial. Acad Med 89, 774

Pfund C, House S, Spencer K, Asquith P, Carney P, Masters KS, McGee R, Shanedling J, Vecchiarelli S, Fleming M (2013). A research mentor training curriculum for clinical and translational researchers. Clin Transl Sci 6 , 26-33

Pfund C, Pribbenow CM, Branchaw J, Lauffer SM, Handelsman J (2006). The merits of training mentors. Science 311, 473.

Rodwell L, Lee KJ, Romaniuk H, Carlin JB (2014). Comparison of methods for imputing limited-range variables: a simulation study. BMC Med Res Methodol 14, 1.

Russell SH, Hancock MP, McCullough J (2007). Benefits of undergraduate research experiences. Science 316, 548-549. 
Schultz PW, Hernandez PR, Woodcock A, Estrada M, Chance RC, Aguilar M, Serpe RT (2011). Patching the pipeline: reducing educational disparities in the sciences through minority training programs. Educ Eval Policy Anal 33, 95-114.

Seymour E, Hunter AB, Laursen SL, DeAntoni T (2004). Establishing the benefits of research experiences for undergraduates in the sciences: first findings from a three-year study. Sci Educ 88, 493-534.

Stuber JM (2011). Inside the College Gates: How Class and Culture Matter in Higher Education, Lanham, MD: Lexington.

Thiry H, Laursen SL (2011). The role of student-advisor interactions in apprenticing undergraduate researchers into a scientific community of practice. J Sci Educ Technol 20, 771-784.

Thiry H, Laursen SL, Hunter AB (2011). What experiences help students become scientists? A comparative study of research and other sources of personal and professional gains for STEM undergraduates. J Higher Educ 82, 357-388.
Thiry H, Weston TJ, Laursen SL, Hunter AB (2012). The benefits of multi-year research experiences: differences in novice and experienced students' reported gains from undergraduate research. CBE Life Sci Educ 11, 260-272.

Undergraduate Research Student Self-Assessment (2009). Ethnography \& Evaluation Research, University of Colorado at Boulder, Boulder, CO. www.salgsite.org (accessed 27 June 2016).

UTEP CIERP (2014). Data Resources, Center for Institutional Evaluation Research and Planning. http://irp.utep.edu/cierp.

Villarejo M, Barlow AE, Kogan D, Veazey BD, Sweeney JK (2008). Encouraging minority undergraduates to choose science careers: career paths survey results. CBE Life Sci Educ 7, 394-409.

Walpole M (2003). Socioeconomic status and college: how SES affects college experiences and outcomes. Rev High Ed 27, 45-73.

Weston TJ, Laursen SL (2015). The Undergraduate Research Student Self-Assessment (URSSA): validation for use in program evaluation. CBE Life Sci Educ 14, ar33. 